\title{
The Influence of Ionizing Beta Radiation on the Flammability Index and Ignition Tempera- ture of Thermoplastic Materials
}

\author{
Martin Bednarik ${ }^{1}$, Ales Mizera ${ }^{2}$, Martin Ovsik ${ }^{1}$ \\ ${ }^{1}$ Faculty Faculty of Technology, Tomas Bata University in Zlín. Vavrečkova 275, 76272 Zlín. Czech Republic. E-mail: \\ mbednarik@utb.cz,ovsik@utb.cz,hylova@utb.cz \\ ${ }^{2}$ Faculty of Applied Informatics, Tomas Bata University in Zlín. Nad Stráněmi 4511, 76005 Zlín. Czech Republic. E- \\ mail: mizera@utb.cz
}

Irradiation of polymeric materials is a modern method of modifying their final properties (for example, improvements in mechanical, thermal and chemical properties). The main used types of radiation to modify polymers include ionic and ionizing radiation. Due to its properties, ionization beta (electron) radiation is the most widely used. The interaction of ionizing radiation with polymeric materials manifests as radiation cross-linking, which is a result of recombination of migrating polymer radicals into the amorphous region. In this type of radiation, electrons are generated under high vacuum using a hot cathode. Electrons emitted from the cathode are then accelerated in the electrostatic field that arises between the cathode and the anode. The depth of penetration into the material rises with increasing energy of electrons. This study examines the influence of ionizing beta radiation on the flammability index and ignition temperature of thermoplastic materials.

Keywords: Flammability Index, Ignition Temperature, Ionizing Beta Radiation, Irradiation, Thermoplastic Materials

\section{Introduction}

Polymeric materials have a very specific properties and because of that they find the use almost in all industrial branches. From the chemical point of view the polymers and elastomers are flammable substances and many times they contribute to a fire. Primarily, the problem is in their ignition temperature, which is at basic polymers around $400{ }^{\circ} \mathrm{C}$. In addition, they can promote expansion due to the melting because the drops temperature is very high (moving around $200{ }^{\circ} \mathrm{C}$ ).

The specific use of these materials is in the electrotechnics and automotive. Just in these branches is the risk of fire higher. Burning and flowing of polymer can be caused by the influence of the short circuit of the electrical circuit or by the high temperature near the engine. From this point of view, the correct choice of the materials or their appropriate modification is essential. [1, 2, 3]

One of the suitable methods of polymers modification is the irradiation. The use of this method requires a full un-derstanding of the effects of radiation on polymeric materials that aim to improve their properties for industrial appli-cations. The main radiation types which are mostly used to polymers modification include ionic and ionizing radiation. Ionizing radiation also includes gamma radiation from the Co-60 radioactive isotope $\left({ }^{60} \mathrm{Co}\right)$, beta (electron) radiation and X-rays. All of these types differ greatly from each other, but all of them transmit energy to the atoms of the irradiated material. For its properties (especially higher radiation velocity), ionizing beta radiation is the mostly used radiation for polymers modification. [3-8]

The majority part of previous studies $[3,9,10]$, which are concentrated on the effect of irradiation on resulting properties of polymeric materials, are primarily determined for the description of structural changes, mechanical properties and chemical stability in the dependence on the radiation dose. Nevertheless, the effect of this type of modification on the flammability of the polymeric materials, especially the flammability index and ignitability, was not examined yet.

This study deals with the effect of ionizing beta radiation on the flammability index and the ignitability of one type of polypropylene and two types of polyamides reinforced with glass fibres.

\section{Material and Methods}

\subsection{Materials}

For this experiment, which deals with the influence of ionizing beta radiation on the flammability and ignitability, two types of polymaides and one type of polypropylene were chosen. All selected types of materials are reinforced with glass fibres and are produced by the PTS (Plastic Technologie Service) company. The trade name of selected materials are:

- $\quad$ PA 6.6 - $30 \%$ GF (V-PTS-CREAMIDA3H7.2G6*M0129A),

- PA 7T - $56 \quad \% \quad$ GF (V-DURAMIDTH7G12.0SZB*9207).

- $\quad$ PP copolymer - 30 \% GF (V-PTS-CREALENEP8G6H3S/L*M800

Test pieces were made using injection molding on the Arburg Allrounder $420 \mathrm{C}$. The shape and dimensions are shown in Fig. 1. In order to improve the resistence to flammability and ignitability, the test bodies were treated with ionizing beta radiation.

The irradiation was carried out in Germany in cooperation with $\mathrm{BGS} \mathrm{GmbH} \& \mathrm{Co}$. KG. The source of beta (electron) radiation was the Rhodotron high-voltage accelerator with a maximum energy of $10 \mathrm{MeV}$ (radiation doses: 33, 66, 99, 132, 165, and $198 \mathrm{kGy}$ ). 

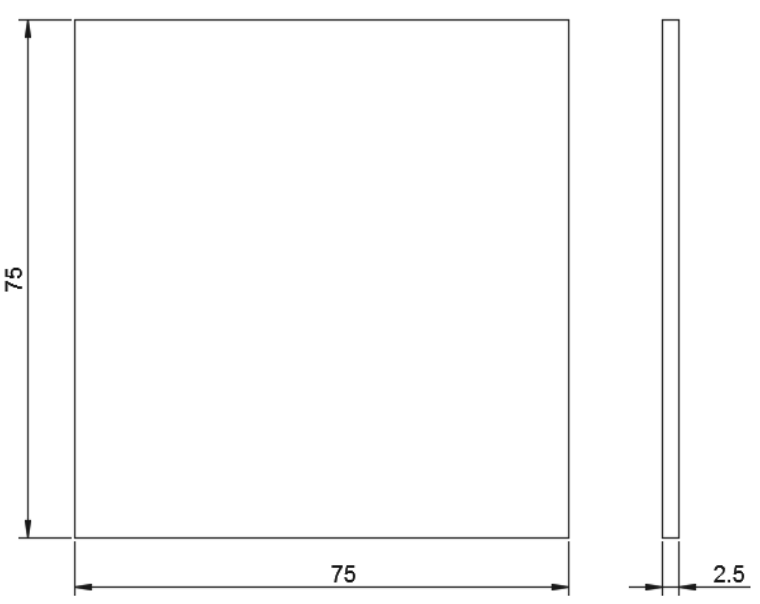

Fig. 1 Test specimen

\subsection{Measurement of flammability and ignitability}

The measurement of the flammability and the ignitability was determined using the method of the hot loop ac-cording to CSN EN 60695-2-12 and CSN EN 60695$2-13$. The source of the polymer ignition is a resistance wire in the form of an electric current loop at a given temperature in the range of $550{ }^{\circ} \mathrm{C}$ to $960{ }^{\circ} \mathrm{C}$. The fixed test body is put into the contact with the torque loop by $1 \mathrm{~N}$ for 30 seconds and imitates the influence of heat stress caused by electrical influences (current overload, faulty joints). This stress can then cause the flame formation or the spread. After removal of the hot loop from the test material, burning or firing time is recorded. The Glow Wire Flammability Index (GWFI) is evaluated for testing according to CSN EN 60695-12 and the Glow Wire Ignition Temperature (GWIT) is determined according to CSN EN 60695-2-13.

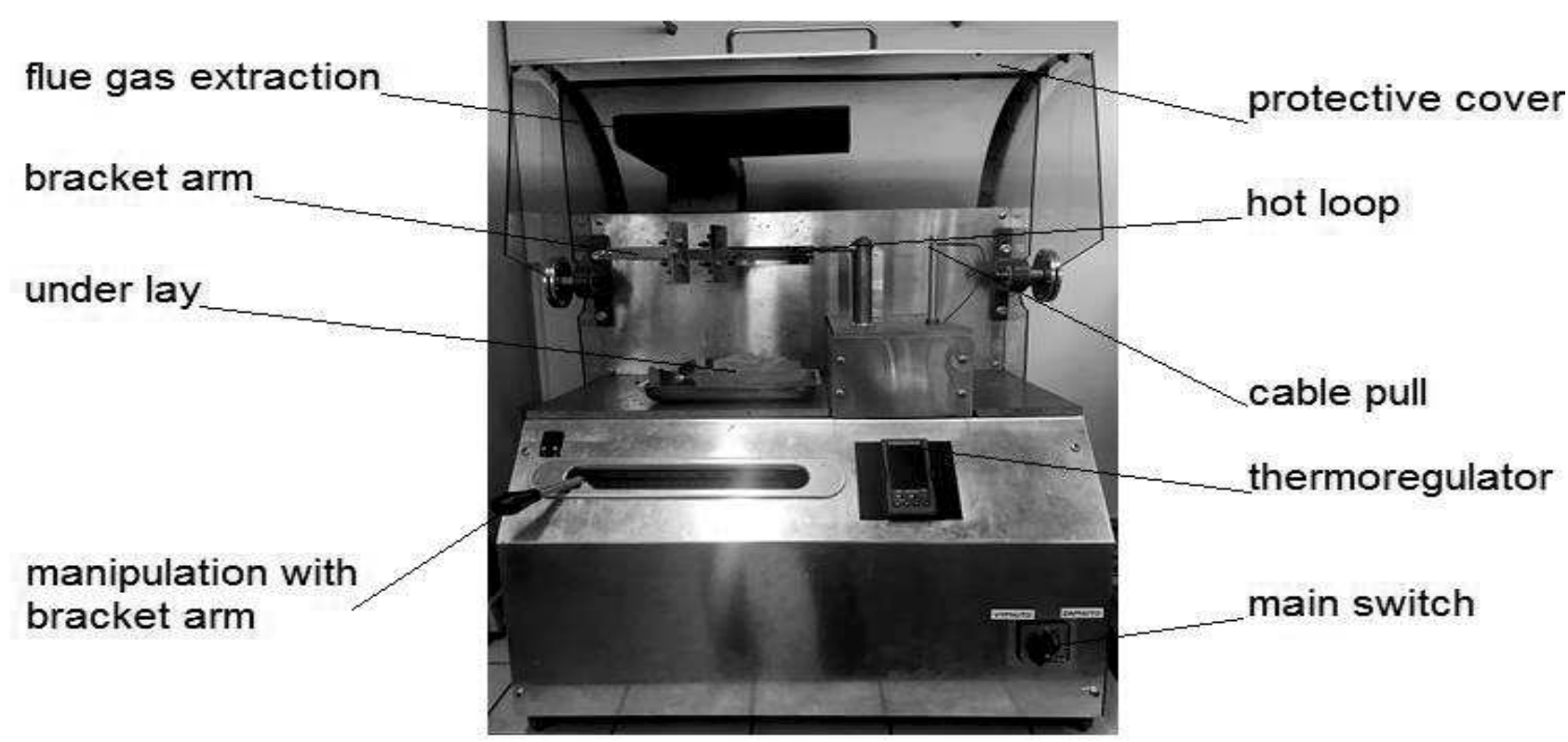

Fig. 2 Testing equipment - hot loop

\section{Results}

\subsection{Material PA 6.6 - $30 \%$ GF}

At non-modified PA 6.6 at $650{ }^{\circ} \mathrm{C}$ there is a significant melting of the plastic together with the gray smoke creation (but not firing). If this material is tested at higher test temperatures, a yellow-orange flame occurs at temperatures above $800{ }^{\circ} \mathrm{C}$ reaching a height of more than $100 \mathrm{~mm}$. After the firing loop is removed from the test body, the firing intensity decreases (but not the complete flame extinction). For this reason, the GWFI and GWIT values are not different. There is no firing of the pad due to the dripping of the material.

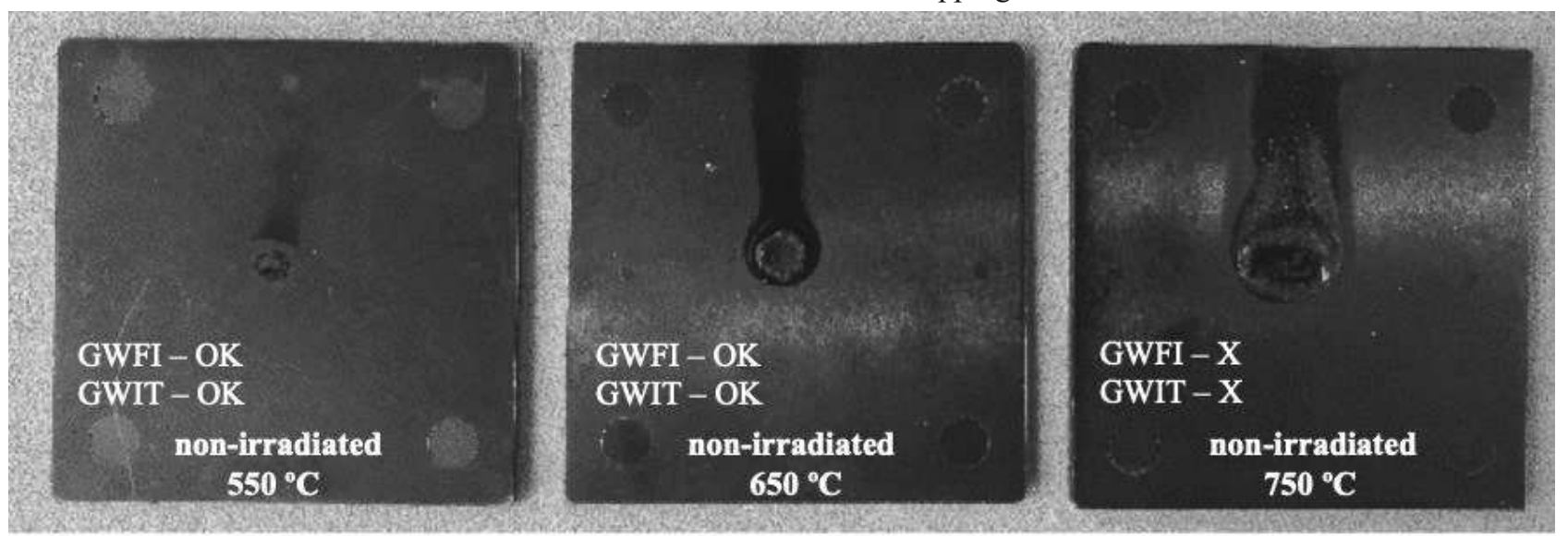




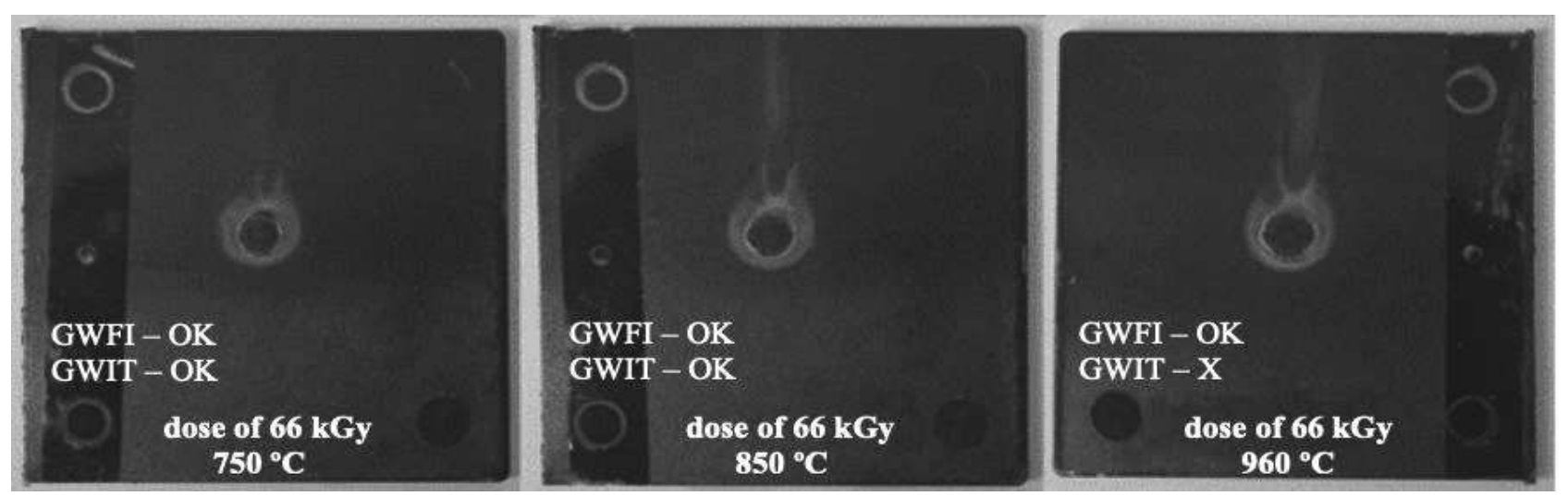

Fig. 3 Test specimens (material PA $6.6-30 \%$ GF) after testing

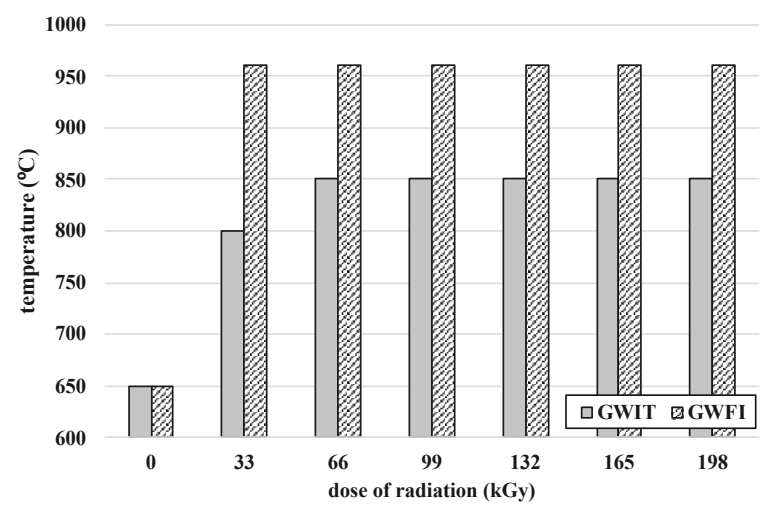

Fig. 4 GWFI and GWIT-material PA 6.6-30\% GF

Even at the lowest radiation dose ( $33 \mathrm{kGy})$, this material has been subjected to a sharp increase in resistance against burning and flammability. The highest possible flammability index $\left(960{ }^{\circ} \mathrm{C}\right)$ is reached at the same dose
(33 kGy). The highest ignition index values (GWIT) are achieved at a radiation dose of $66 \mathrm{kGy}$, an increase of 200 ${ }^{\circ} \mathrm{C}$ (compared to non-irradiated material). For PA 6.6, the GWFI and GWIT appear to be the most appropriate radiation dose of $66 \mathrm{kGy}$ (Fig. 3 and 4). Irradiation of PA 6.6 with higher radiation doses brings only higher financial cost of the entire process without a de-monstrable increase in GWFI and GWIT values.

\subsection{Material PA 7T - $56 \%$ GF}

During testing non-modified PA 7T material, a flammability index of $750{ }^{\circ} \mathrm{C}$ was found. At this temperature there was a brief flare of material, but the flame was extinguished after a flame had been extinguished, reaching a height of approximately 30 millimeters. The GWIT value was $700^{\circ} \mathrm{C}$ for unmodified PA 7T material, which is $50{ }^{\circ} \mathrm{C}$ more than that at non-modified PA 6.6 (Fig. 5 and $6)$.
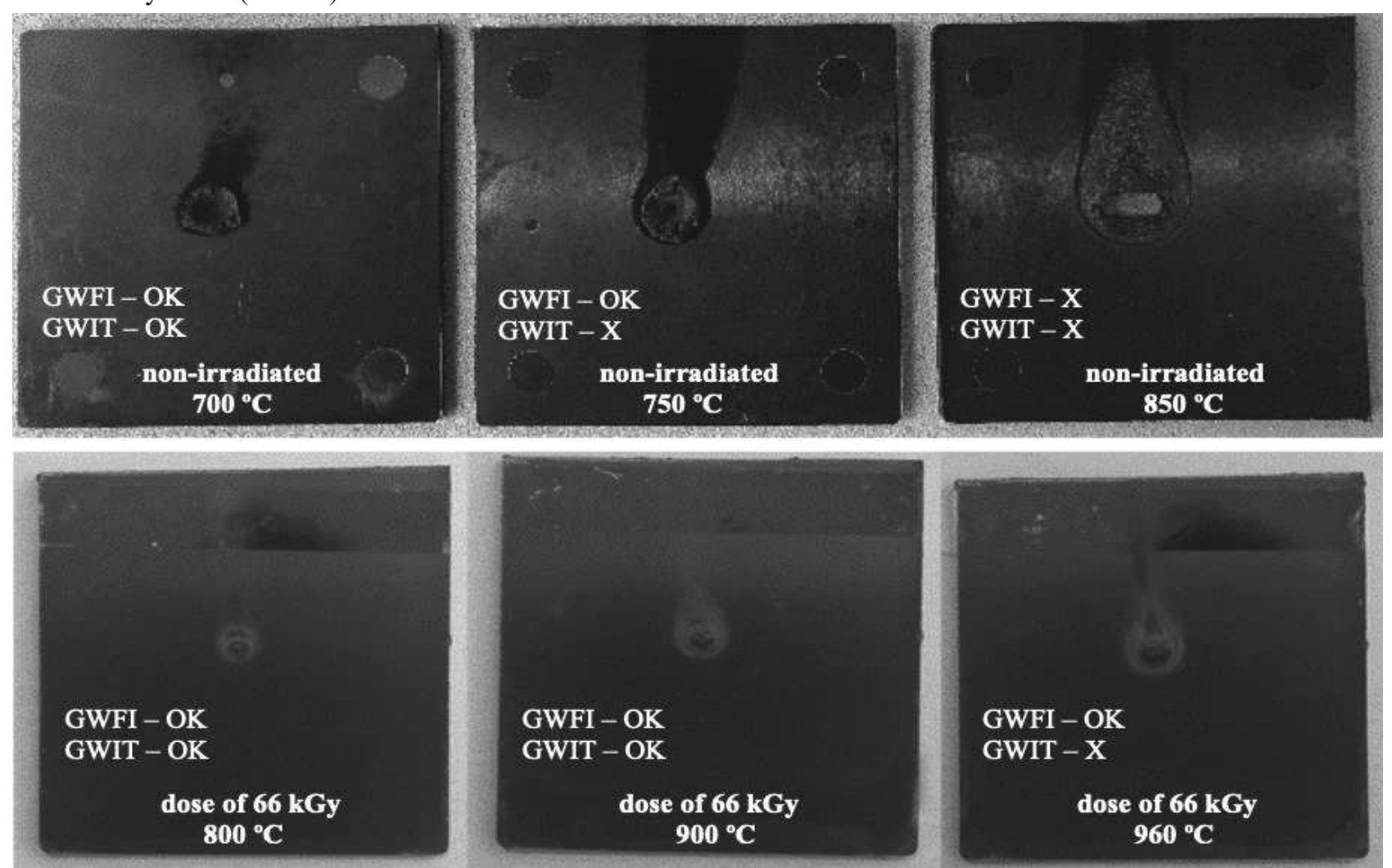

Fig. 5 Test specimens (material PA 7T-56\% GF) after testing 


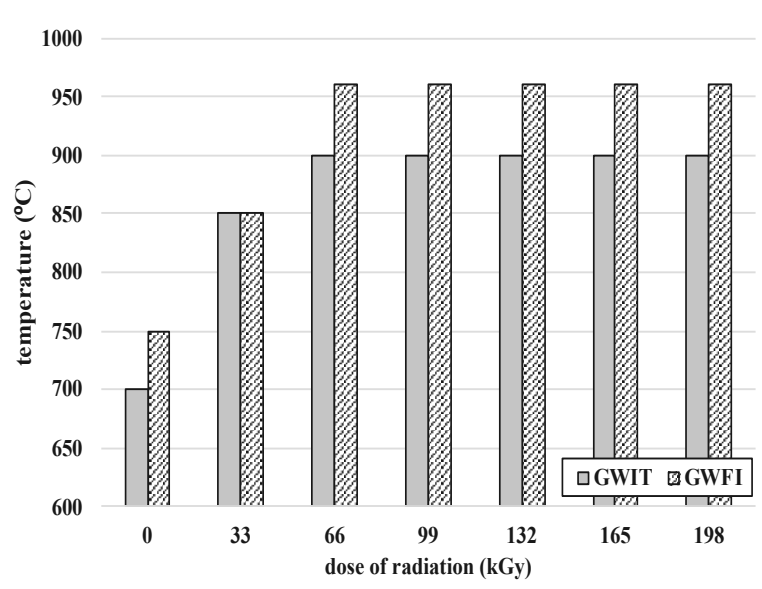

Fig. 6 GWFI and GWIT-material PA $7 T-56 \% G F$

As with the first tested material (PA 6.6), the radiation exposure significantly increases the GWFI and Ignition
Index (GWIT). The highest increase is achieved at the radiation dose of 33 and $66 \mathrm{kGy}$.

However, when comparing two tested parameters, the radiation dose of $66 \mathrm{kGy}$ appears to be the most suitable for the modification of the PA 7T material. When PA 7T is irradiated, GWIT index rises to $900{ }^{\circ} \mathrm{C}$, an increase of $200{ }^{\circ} \mathrm{C}$ (compared to non-modified material). Flammability index increases to $960^{\circ} \mathrm{C}$, increasing by $210^{\circ} \mathrm{C}$ (compared to non-modified one). Once modified, the material (66 kGy) after the firing of the hot loop ceases to burn within a few seconds. The flame at this temperature is about 10 to 15 millimeters in size. Higher radiation doses are shown by reducing flame size (Fig. 5 and 6).

\subsection{Material PP copolymer - 30 \% GF}

In the case of an non-modified test piece of PP material, the flame ignition temperature was $650^{\circ} \mathrm{C}$ during the test. After evaluating measured results, GWIT was set at $600{ }^{\circ} \mathrm{C}$. The Flammability Index was also found to be 600 ${ }^{\circ} \mathrm{C}$ be-cause at this temperature the plate was only melted by a glowing loop (not burning).
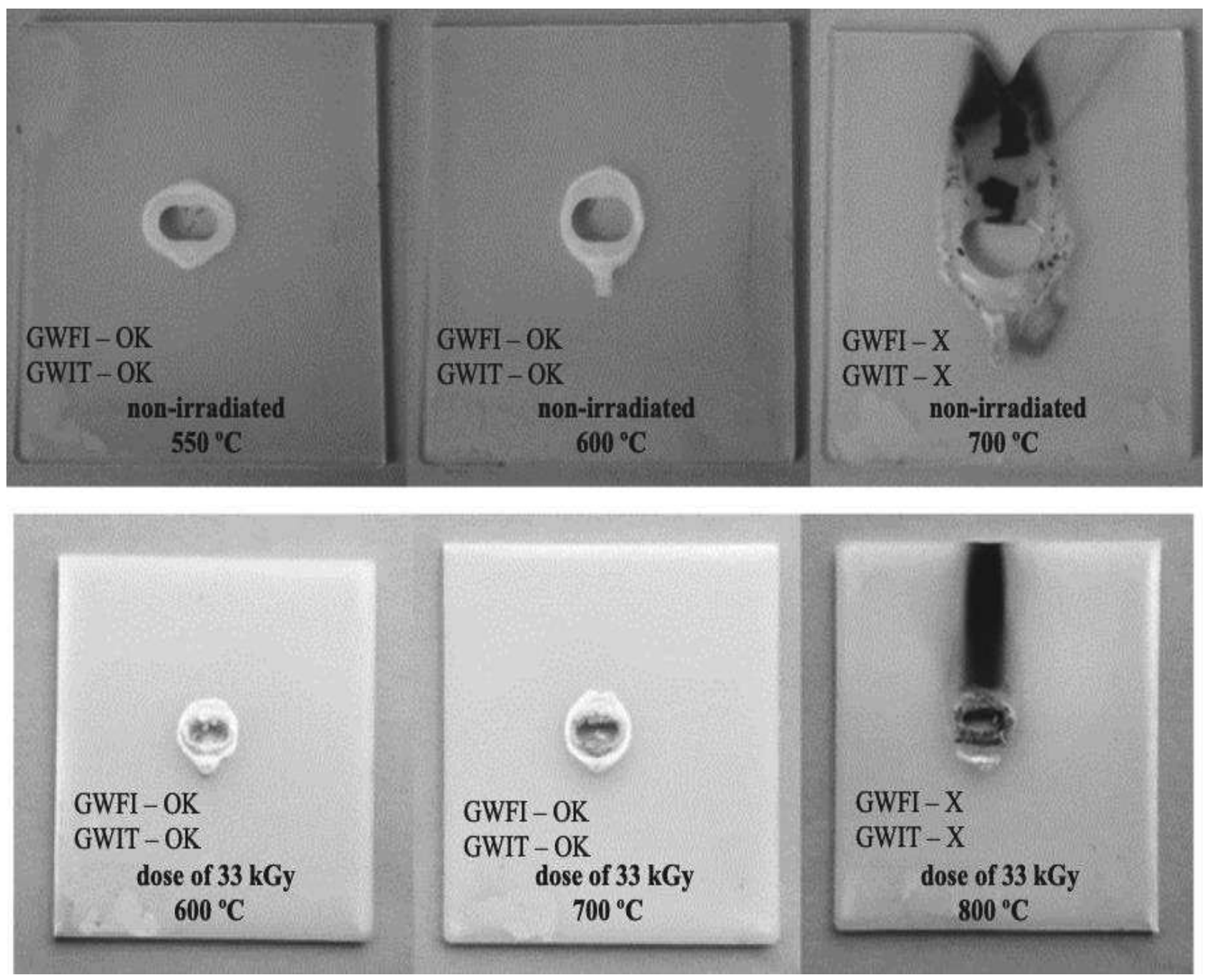

Fig. 7 Test specimens (material PP copolymer - 30\% GF) after testing

After irradiation of the test specimens, the temperature of $700{ }^{\circ} \mathrm{C}$ was increased for both test parameters. The increasing radiation dose no longer has any effect on the
GWIT and GWFI values (only flame intensity and flame size decrease) (Fig. 7 and 8). 


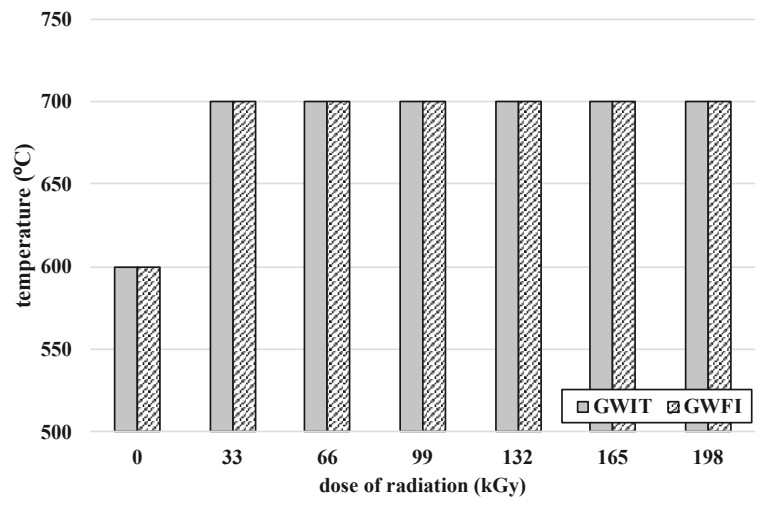

Fig. 8 GWFI and GWIT - material PP copolymer - 30 $\% G F$

\section{Conclusion}

In this study, the effect of radiation cross-linking on two basic safety parameters, GWFI and GWIT for two types of polyamides and one type of polypropylene, was studied. The investigated types of materials were reinforced with glass fibers of various concentration. As mentioned earlier, the burning and creeping of the polymer may be due to an electric current short circuit or high temperature near the engine. From this specimen, the right choice of material or its ap-propriate modification is very important.

From measured results, ionizing beta radiation appears to be a more effective way to increase the resistance against ignition (GWIT) and flammability (GWFI). For all studied materials, the increase was evident at the lowest dose of radiation. However, the dose of $66 \mathrm{kGy}$ for both types of polyamides is the most appropriate radiation dose. GWFI increased to $960{ }^{\circ} \mathrm{C}$ (for both polymers) and GWIT to $850{ }^{\circ} \mathrm{C}$ (for PA 6.6) and $900{ }^{\circ} \mathrm{C}$ (for PA7T) at this dose.

For PP material, the increase was not as significant as the polyamides examined. With this type of material, 33 $\mathrm{kGy}$ appears to be the most suitable radiation dose. At this dose, the two parameters examined (GWFI and GWIT) increased to $700{ }^{\circ} \mathrm{C}$. These increases in GWFI and GWIT values are probably due to primary and secondary processes (such as ionization, free radical formation, cross-linking, etc.) occurring in the material as a result of irradiation.

\section{Acknowledgement}

This work was supported by the Internal Grant Agency of TBU in Zlin: no. IGA/FT/2018/012.

\section{References}

[1] MURRAY, K. A, KENNEDY, J. E., et al. (2012). The effects of high energy electron beam irradiation on the thermal and structural properties of low density poly-ethylene. In: Radiation Physics and Chemistry, Vol. 81, pp. $962-966$.

[2] GHEYSARI, Dj., BAHJAT, A., et al. (2001). The effect of high-energy electron beam on mechanical and thermal properties of LDPE and HDPE. In: European Polymer Journal, Vol. 37, pp. 295 302.

[3] MIZERA, A., et al. (2014). Temperature stability of modified PBT by radiation cross-linking. In: Advanced Materials Research, Vol. 1025-1026, pp. $256-260$. TTP. Switzerland.

[4] MAKUUCHI, K., CHENG, S. (2012). Radiation Processing of Polymer Materials and its Industrial Applications, p. 515 Hoboken Publisher, N.J.: Wiley.

[5] DROBNY, J. G. (2013). Ionizing Radiation and Polymers: Principles, Technology and Applications, p. 298 Oxford: Elsevier Publisher, William Andrew.

[6] MATLAK, J., et al. (2016). Electron beam surface quenching of X37CrMoV51 tool steel swages. In: Manufacturing Technology, Vol. 16, pp. 744-749.

[7] MATLAK, J., DLOUHY, I. (2018). Properties of electron beam hardened layers made by different beam deflection. In: Manufacturing Technology, Vol. 18, pp. 279-284.

[8] FOUSOVA, M., VOJTECH, D. (2018). Possibilities of electron beam melting technology: Titanium processing. In: Manufacturing Technology, Vol. 18, pp. 387-393.

[9] BEDNARIK, M., et al. (2013). Effect of beta irradiation on the strength of bonded joints of HDPE. In: Key Engineering Materials, Vol. 586, pp. 79 82. TTP. Switzerland.

[10] NAVRATIL, J., MANAS, M., et al. (2015). Recycling of irradiated high-density polyethylene. In: Radiation Physics and Chemistry, Vol. 106, pp. $68-72$.

\subsection{2/ujep/394.2019/a/1213-2489/MT/19/6/907}

Copyright (C) 2019. Published by Manufacturing Technology. All rights reserved. 